\title{
ПРИМЕНЕНИЕ МЕТОДА ПЕРЕВЕРНУТОГО ОБУЧЕНИЯ В ДИСТАНЦИОННОМ ВУЗОВСКОМ ОБУЧЕНИИ ДЕЛОВОГО РУССКОГО ЯЗЫКА
}

\section{VIKTORIA VRÁŽELOVÁ, LENKA ALIEVA}

\section{THE APPLICATION OF A FLIPPED CLASSROOM METHOD TO THE UNIVERSITY DISTANCE TEACHING OF BUSINESS RUSSIAN}

ABSTRACT The paper deals with the problematics of the flipped classroom method in distance university education. It describes the differences between traditional and innovative forms of teaching in the course of business Russian outlining their main advantages and disadvantages. The emphasis is put on the application of the flipped classroom method in an online distance course as well as on the analysis of the data obtained from a questionnaire.

KEY WORDS flipped classroom, university distance teaching, taxonomy of educational objectives

CONTACT Кафједра языков Технического университета в г. Кошице, Словацкая pecnyблика; viktoria.vrazelova@tuke.sk,lenka.alieva@tuke.sk. 


\section{$1 /$ ВВЕДЕНИЕ}

Настоящее время ставит перед преподавателями иностранных языков различные задачи. Одной из них стал период вынужденного перехода на дистанционное обучение в нашем университете, который длился весь летний семестр 2019/2020. По сравнению с традиционным очным обучением в университетах все большее значение приобретают различные информационные технологии и инновационные методы обучения. Преподаватели в сегодняшние нестабильные времена, когда традиционное обучение внепланово чередуется с дистанционным, должны оперативно реагировать и адаптировать свои учебные программы и методы. В первую очередь им необходимо переосмыслить свой традиционный стиль преподавания и найти способы более эффективного преподнесения и практической реализации учебного плана. Ориентация на более интерактивные формы обучения, которые направлены на потребности студента, становятся неотъемлемой частью современной системы образования. В связи с ростом образовательных технологий все больше набирает популярность метод так называемого перевернутого класса, суть которого заключается в обменном проведении занятий, в школе и дома. В статье рассматривается концепция перевернутого обучения, история развития концепции и сравнение традиционной модели обучения с перевернутым обучением. Представляется собственный педагогический опыт с реализацией метода на курсах русского языка как иностранного у студентов Экономического факультета. Целью нашего исследования является изучение восприятия и оценки студентами метода на основе результатов анкетирования.

\section{2 / ИСТОРИЯ РАЗВИТИЯ МЕТОДА ПЕРЕВЕРНУТОГО ОБ- УЧЕНИЯ}

Концепция так называемого «перевернутого обучения» (по англ. Flipped Classroom или Inverted Classroom) представляет собой молодой по дидактическим меркам образовательный феномен. Некоторые русские авторы предпочитают называть этот термин, вместо калькированного перевода «перевернутый класс» или «перевернутое обучение», русскоязычным эквивалентом «обратное обучение» (Атабекова - Белоусов 2013). В нашей статье будем пользоваться термином перевернутое обучение, так как это нам намекает иностранное происхождение этой образовательной модели.

Концепция обучения была сформулирована и успешно реализовалась представителями зарубежного академического сообщества. Публикации с примерами реализации этой образовательной технологии и первыми теоретическими обобщениями по данной проблематике появились в конце 90-х годов XX века. Среди основателей концепции перевернутого обучения необходимо упомянуть американских вузовских специалистов по экономике М. Лейджа, Г. Плата и М. Треглию (2000), которые пришли к выводу, что обучение становится эффективным, когда действия, традиционно выполняемые во время обучения, проходят вне класса. При внедрении этого метода они уделяют основное внимание носителям информации, которые являются его краеугольным камнем. В домашних заданиях студентов они рекомендовали использовать видеозаписи лекций или презентации PowerPoint co звуком, которые были опубликованы в Интернете. Ожида- 
лось, что студенты курса Микроэкомомика в университете в Майами придут в класс подготовленными к обсуждению соответствующего материала. На занятиях студенты были готовы провести в группе экономические эксперименты и «имели возможность увидеть экономические принципы в действии» (Lage - Platt - Treglia 2000: 33).

Затем идею этой модели обучения подхватил и Салман Хан, который в 2004 году стал создавать видео, чтобы помочь своим родственникам в учебе, когда они не преуспевали в математике. Репетиторство с помощью телефона и приложения Yahoo Doodle было так эффективным, что первоначальная идея помощи родственникам переросла в создание учебного заведения «Академия Хана» (Khan Academy) в 2008 году. Этот образовательный ресурс включает более 3000 видеолекций по различным дисциплинам естественных, инженерных, гуманитарных наук, которые размещаются на платформе YouTube. Эта обучающая платформа делает упор на персонализированном обучении, когда студенты практикуют учебную программу в своем собственном темпе, заполняют пробелы в понимании учебной программы и таким образом ускоряют свое обучение.

К настоящему времени начинают появляться единичные публикации по исследуемой инновационной модели обучения у русских авторов. Собственный опыт применения технологии перевернутого обучения описывают преподаватели Южно-Уральского государственного университета в Челябинске, М. В. Цытович и Г. Ф. Бороненко, которые этот метод применили при обучении английскому академическому письму. В экспериментальной группе были преподаватели и аспиранты вуза, и их обучение происходило по традиционной методике и с использованием инновационных технологий. Учащиеся получили на дом теоретический материал в формате Pdf, подкасты для академического письма, упражнения для расширения словарного запаса, дополнительные видеоматериалы и ссылки. В конце каждого теоретического модуля проводился онлайн тест с вопросами с несколькими вариантами ответов. На очных занятиях студенты выполняли различные продуктивные действия, напр. анализ конкретных академических текстов, поиск ошибок в текстах, сравнение исходной и исправленной версий текста, различные грамматические и лексические упражнения. Результаты исследования Цытовича и Бороненка показали, что «при прохождении одинакового количества теоретического материала в два раза увеличилось количество практических упражнений, выполняемых на занятии, а также увеличилось количество усвоенных лексических единиц». Количество новых лексических единиц увеличилось благодаря интерактивным лексическим упражнениям на 300 до 350 слов в сравнении с 200 словами усвоенными при использовании традиционного метода. (Цытович - Бороненко 2018: 62).

Наконец, мы хотели бы упомянуть, что существенный вклад в методологическую разработку концепции перевернутого обучения внесли работы учителей химии Д. Бергмана и А. Сэмса, которые популяризировали данный метод в мире и воплотили «перевёрнутые» уроки в практику. Д. Бергман и А. Сэмс нашли решение, как обеспечить своими лекциями студентов, часто пропускающих занятия. Применение этого решения было мотивировано также и тем, что они расходовали непомерно много времени на проведение повторных занятий для студентов, пропустивших занятия. Поэтому они начали размещать их онлайн-лекции в форме видео, чтобы и отсуствующие студенты имели к ним доступ. В результате видеолекций возможность их просмотра в режиме онлайн 
оценили как отсуствующие, так и остальные присутствующие на занятии студенты. Позитивные отзывы от студентов привели американских педагогов к соответствующему выводу о том, что можно радикально изменить временной принцип проведения занятий (Bergman - Sams 2012).

В их совместном труде Flip your classroom (2012) авторы описали метод перевернутого обучения как учебную стратегию на основе которой то, что должно было быть реализированным в классе, сейчас было проведено дома, и наоборот, домашние задачи стали быть реализированы в классе. Основным при этом моделе обучения является то, что учитель предоставляет новый учебный материал для самостоятельного изучения дома, а на очном занятии проходит практическое закрепление нового материала (Bergman Sams 2012: 13). Важно то, что авторам удалось сосредоточить свое внимание на методе перевернутого обучения в связи со значительным изменением позиции учителя во время обучения. Мы замечаем переход от главенства учителя к главенству студента. Студенты принимают на себя отвественность за их собственное обучение, так как применение этого нового метода предоставляет определенную степень выбора при выполнении их домашних заданий. С другой стороны, учителя перестают занимать позицию носителя информации, и их роль заключается в управлении и наблюдении за студентами. Учителя становятся «гидами» студентов, создавая им больше пространства для активности и реализации. Наблюдается принципиальное изменение содержания очного занятия. Оно не начинается вводной теоретической лекцией преподавателя, а сосредотачивается на работе студентов в парах, в группе или на интерактивной беседе (Bergman - Sams 2012: 27).

Кроме значительного изменения позиции учителя перевернутое обучение связано с комплексной реструктуризацией времени обучения. В начале очного занятия учитель ведет дискуссию, задает студентам вопросы относительно темы объясненной в видео и отвечает на вопросы студентов. Все остальное время учитель уделяет внимание продолжительным видам деятельности, как например решению проблем и практическим занятиям. В Таблице 1 приведена длительность отдельных этапов урока в сравнении традиционное обучение против перевернутого обучения (Bergman - Sams 2012: 15).

\begin{tabular}{llll}
\hline Традиционное обучение & & Перевернутое обучение \\
\hline Деятельность & Время & Деятельность & Время \\
\hline Вводные действия & 5 мин. & Вводные действия & 5 мин. \\
\hline Контроль домашнего задания & 20 мин. & $\begin{array}{l}\text { Дискуссия о домашнем задании } \\
\text { в форме видеоролика }\end{array}$ & 10 мин. \\
\hline $\begin{array}{l}\text { Объяснение нового учебного } \\
\text { материала }\end{array}$ & 30-45 мин. & $\begin{array}{l}\text { Управляемая и независимая практика } \\
\text { или лабораторная деятельность }\end{array}$ & 75 мин. \\
\hline
\end{tabular}

Управляемая и независимая

20-35 мин.

практика или лабораторная

деятельность

Таблица 1. Сравнение использования времени в традиционном и перевернутом обучении (Bergman, Sams) 


\section{З / МЕТОД ПЕРЕВЕРНУТОГО ОБУЧЕНИЯ С ТОЧКИ ЗРЕНИЯ ТАКСОНОМИИ БЛУМА}

Д. Бергман разрабатывает проблематику другого использования времени в традиционном и обратном обучении и в других научных работах. На своих видеолекциях призывает учителей переоценить время, используемое в классе, совмещая изменения в способе обучения с необходимыми изменениями в таксономии Блума (Bloom, 1956, с. 201-207). Касательно применения иерархии образовательных целей он предлагает отделить два нижних уровня таксономии Блума (знание и понимание) от очного обучения и перенести их в среду домашней подготовки студентов в форме видео. Он оправдывает это тем, что именно выполнение целей этих двух уровней занимает больше всего времени в традиционном классе, а на темы других уровней (применение и оценка) выдяляется намного меньше времени, или время отсутствует. В Таблице 2 слева показана иерархия целей в традиционном обучении, которая начинается со знаниями и окончается с оценкой. В Таблице 2 направо показана желаемая обратная иерархия в обучении по мнению Бергмана с упором на применение и оценку, которые должны стать основными компонентами дидактической структуры урока. Бергман объясняет, что «когда мы пересмотрим таксономию Блума, мы будем уделять больше времени существенным темам из высших слоев иерархии, которые требуют более высокого уровня мыслительных действий» (Бергман 2013).

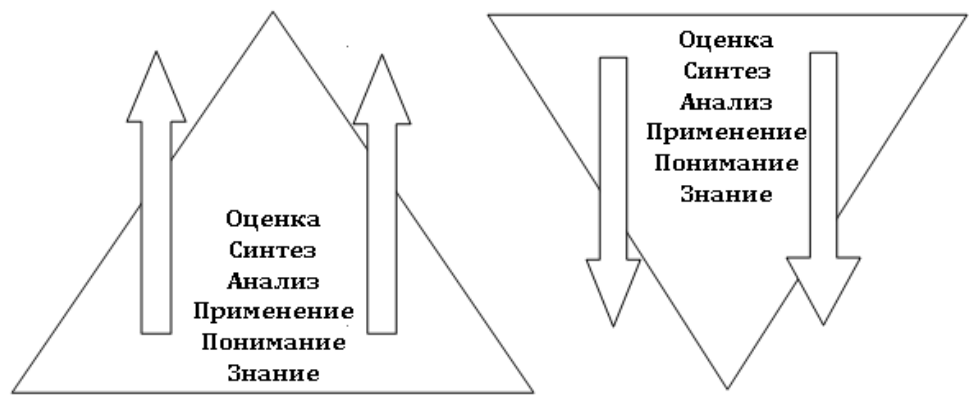

Таблица 2. Переоценка времени в классе на примере таксономии Блума (Бергман)

\section{4 / МЕТОД ПЕРЕВЕРНУТОГО ОБУЧЕНИЯ В ДИСТАНЦИ- ОННОМ ВУЗОВСКОМ ОБУЧЕНИИ ДЕЛОВОГО РУССКОГО ЯЗЫКА}

Постоянные изменения обстоятельств в обучении студентов вуза (переход из очного на заочное обучение в течение одного семестра) требуют создания новых решений и использования информационно-коммуникативных технологий в обучении. По нашему мнению, потребностям студентов во время вынужденного дистанционного обучения наиболее эффективно отвечает модель перевернутого обучения.

Основным преимуществом этого метода является соединение традиционного обучения с домашним обучением, когда преподаватель гибко планирует занятия, разделенные на дневное обучение и домашнее онлайн-обучение. В условиях дистанционного 
обучения мы не могли полностью использовать потенциал этого метода, так как очное обучение не было реализовано из-за пандемии коронавируса. Изменившиеся условия обучения создали вынужденную ситуацию для адаптирования нами метода перевернутого обучения в новых условиях, когда все обучение переместилось только в домашнюю среду студента. В нашем исследовании мы использовали метод перевернутого обучения, который мы применили исключительно к дистанционной форме обучения, без возможности очного обучения студентов. Из-за необходимости дистанционного обучения, которое мы реализовали в летнем семестре академического года 2019/2020, мы создали собственную методику обучения, вдохновленную методом перевернутого обучения. Основное отклонение от метода перевернутого обучения заключется в том, что вся учебная деятельность проходила дома за пределами университетских помещений без прямого взаимодействия с преподавателем. Наша основная цель при использовании этого метода состояла в мотивации студентов к активному обучению с помощью современных привлекательных мультимедийных материалов.

Внедрение метода перевернутого обучения исключительно к дистанционному обучению потребовало высокой личной ангажированности как со стороны преподавателей, так и со стороны студентов. Домашнее онлайн-обучение проходило через платформу Moodle, где преподаватели публиковали один раз в неделю все подготовленные рабочие материалы. Наша подготовка к дистанционному обучению состояла из нескольких этапов. В первую очередь это была задача создания подходящего учебного материала к учебнику Русский язык для делового общения А2 (Котане 2014). Рабочие материалы летнего семестра в соответствии с учебником содержали темы: Клиенты, Деловая встреча, Рынок, Конкуренция и Бренды. Мы сами подготовили рабочие материалы к этим темам в форме Ворд документов. В структуру материалов к учебнику входили следующие учебные задания: аудирование и дополнение недостающей информации в диалогах, послетекстовые и последиалоговые ответы на вопросы, дополнение типичной характеристики продуктов, образование словосочетаний в правильной падежной форме, перевод словосочетаний на словацкий язык.

Второй задачей был поиск видеоматериалов из канала Youtube, которые были тематически связаны с содержанием учебника. Нашей основной целью было найти короткие видеолекции продолжительностью до 2-3 минут. Третьей задачей была подготовка рабочих материалов к видеолекциям в форме Ворд документов. Содержанием дополнительных видеолекций были понятия подходящие к учебнику (Клиенты: постоянный и лояльный клиент, клиентская база, сарафанное радио, накопительные и дисконтные карты, бонусная система; Деловая встреча: назначение и предложение деловой встречи, соблюдение правил телефонных звонков; Рынок: определение рынка, виды рынков, внутренний и внешний рынок, рыночный механизм, регуляторы поведения субъектов рынка, спрос и предложение, функции рынка; Конкуренция: определение конкуренции, роль конкуренции, основные виды конкуренции, монополия, совершенная и несовершенная конкуренция, олигополия; Бренды: определение бренда, ментальная карта носителей бренда, известные российские бренды).

Целью рабочих материалов к видео было стимулирование студентов к самостоятельной работе дома и обогащение словарного запаса студентов о новые лексические 
единицы, которые не находились в базовом учебнике. Студенты приобретали навыки понимания информации и изучали новые слова и выражения. Структура рабочих матераилов к видео состоит из двух частей. В начале каждой части приводится ссылка на одно видео, русско-словацкий глоссарий терминов, слов и словосочетаний, которые прозвучат в видео и для студентов они новые. В рабочих материалах сосредотачиваем внимание на конкретные задачи, вытекающие из содержания видео. Из информации в видео студенты после просмотра видео разрабатывают 3 или 4 упражнения, направленные на общее понимание и понимание деталей услышанной информации. Считаем, что благодаря выполнению упражнений просмотр видео намного эффективнее. Упражнения состояли из следующих заданий: определение термина на основе толкования, определение верных/неверных утверждений, выбор правильного варианта, соединение словосочетания из правой и левой колонок, дополнение терминов в ментальную карту, исправление ошибок в утверждениях, перевод терминологических словосочетаний на словацкий язык, ответы на открытые вопросы, ответы на закрытые вопросы с вариантами выбора. В Приложении 1 указаны примеры заданий к видео по теме Бренды.

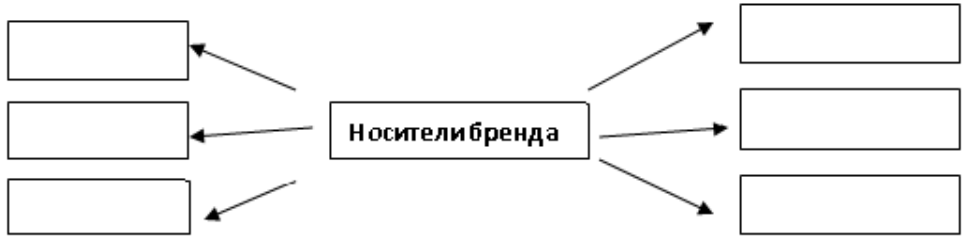

Приложение 1. Примеры заданий к видео по теме Бренды (Вражелова, Алиева)

Задание: Дополните ментальную карту.

Задание: Отметьте, являются ли утверждения верными или неверными.

A: Бренд-это только торговая марка

$B-H$

Б: Бренд - это продукт, вещь или компания

$B-H$

В: Бренд-это ожидание и удовлетворение

$B-H$

Задание: Исправьте неправильную инфбормацию о топ 10 самых известных российских брендах в мире.

1. Лада известна за пределами РФ. Продукиию мохно встретить на дорогах Восточной Европы, Южной Америки и в некоторых государствах Ближнего зарубежья.

2. Аэрофблот крупнейший национальный перевозчик. Компания является одной из самых безопасных в России и пользуется признанием иностранных пассажиров.

3. Компания КамАЗ производит легендарные легковые машины знаменитые по всей Евpone.

.Студенты дома выполняли все учебные задания в документах в Ворде, используя платформу Moodle и канал Youtube. Через платформу Moodle студенты отправляли заполненные рабочие материалы в онлайн-папки платформы Moodle один раз в неделю по расписанию. Непрямое взаимодействие преподавателя со студентом также заключалось в том, что студенты получали отзывы учителя о разработанных рабочих материалах в виде письменных комментариев в онлайн-папке платформы Moodle. Преимущество 
онлайн-обучения заключалось в большей гибкости и свободе для студентов, одним из недостатков для преподавателей была невозможность получить обратную связь от студентов в реальном времени.

Просмотр видеолекций студентами и их регулярная работа на заданиях к видео принесла много преимуществ. Путем просмотра видео студенты развивали словарный запас профессиональных тем, при этом у них была возможность прослушивать речь носителей языка. В качестве предварительной подготовки перед каждым просмотром видео преподаватель предоставил основной перечень слов, словосочетаний, которые содержались в видео касательно конкретной темы. Еще одним преимуществом было то, что студенты могли слушать подлинное произношение носителей языка и повторять его произношение. В отличие от механического обучения словарного запаса, основанного на записях из учебников, просмотр видео значительно изменил понимание профессиональных терминов у учащихся. Из видео студенты создавали ментальные карты, благодаря которым получили более широкий обзор по конкретной теме.

Просмотр видео стимулировал языковые навыки всех учащихся, независимо от их уровня владения языком. Преимущество просмотра видео заключалось в том, что более слабые студенты могли просматривать видео несколько раз, включать просмотр по мере необходимости и убедиться в том, что они правильно поняли содержание. Субтитры, которые использовало 55\% студентов (на основе наших результатов анкетирования), помогли лучше понять содержание. Таким образом, домашняя подготовка способствовала прогрессу в учебе более слабых учеников. Время, которое студенты посвящали самостоятельному изучению русского языка дома, было увеличено по сравнению с очным обучением. Студенты не были ограничены временем академических 90 минут при подготовке рабочих материалов.

\section{5 / ВОСПРИЯТИЕ СТУДЕНТАМИ МЕТОДА ПЕРЕВЕРНУ- ТОГО ОБУЧЕНИЯ (РЕЗУЛЬТАТЫ ИССЛЕДОВАНИЯ)}

Исследование проводилось на Кафедре языков Технического университета в городе Кошице в летнем семестре 2020 года. Обучение методом перевернутого обучения проводилось в трех группах студентов первого курса Экономического факультета. В исследовании приняло участие 39 студентов, завершивших второй семестр дистанционного изучения предмета «Деловой русский язык». Основная цель исследования в форме анкеты заключалась в определении восприятия метода перевернутого класса нашими студентами и эффективности такого обучения. Число опрошенных, заполнивших анкету, составило 22 студента. Анкета включала 16 вопросов: 14 вопросов в форме ответа из нескольких возможностей и 2 открытых вопроса.

Анализ и обработка результатов анкетирования показали, что 100\% из общего числа опрошенных устраивало онлайн обучение, причем 71\% студентов положительно оценивает содержание обучения и метод работы с рабочими материалами приспособленными под домашнее обучение. $73 \%$ студентов отнеслись положительно к содержанию рабочих материалов к учебнику одновременно с дополнительными рабочими материалами включающими видео. Полученные результаты подтверждают эффективность 
использования видеоресурсов. 77 \% студентов считает работу с рабочими материалами с видео более эффективным инструментом изучения иностранного языка по сравнению с традиционной формой обучения. При анализе содержания дополнительных рабочих материалов с видео, почти 60\% опрошенных оценили материалы как интересные. Наши результаты показали, что студенты отдают предпочтение менее сложным типам упражнений (73\% - выберите правильный вариант, 63,6\% - образуйте словосочетания, 59,1\% - отметьте верное/неверное утверждение) по сравнению со сложными упражнениями (дополните определения подходящими словами, находящимися в рамке, ответьте на вопросы, исправьте неправильные утверждения, дополните пропущенные слова в словосочетаниях или предложениях). Анализ ответов опрошенных показал, что хотя $55 \%$ опрошенных прибегало к помощи субтитров, у 73\% из них понимание содержания в видео не вызывало затруднения. В среднем студенты уделяли разработке упражнений 60 минут.

Нашей целью было узнать, к какому прогрессу привела разработка рабочих материалов с видео у студентов. Наши результаты показали, что у студентов улучшились: словарный запас делового РКИ (54,5\% опрошенных), освоение коммуникативных моделей (50\% опрошенных), понимание на слух (86,4\% опрошенных), понимание сущности услышанной информации в плавном темпе речи (50\% опрошенных). По мнению $68 \%$ студентов уделенное время для изучения рабочих материалов в учебнике и дополнительных рабочих материалов с видео помогло успешно сдать устный экзамен по деловому РКИ в конце семестра. Самостоятельная работа отразилась и в результатах зачетного тестирования. Количество студентов первого курса по предмету «Деловой русский язык» с оценкой А и Б увеличилось с $48 \%$ (обучение по традиционной модели в зимнем семестре 2019/2020) на 76\% (обучение по модели перевернутого обучения в летнем семестре $2019 / 2020$.

К примеру приводим несколько комментариев наших студентов:

Я почувствовала личный прогресс в отношении русского языка, чем в зимнем семестре.

Я считаю такой подход хорошей альтернативой обучения языкув домашних условиях.

Рабочие листы с видеозаписями помогли мне лучше понять саму тему.

Я быстрее запоминала новые слова и их произношение.

Я обязательно улучшила свое прослушивание, а также свое произношение, поскольку я прослушивала видеозаписи и слышала иностранный язык у людей, чей язык является родным.

Я выучил слова намного легче и лучше понял тему.

Словосочетания, слова и предложения лучше сохранились в моей памяти благодаря аудио и видеозаписям.

Мне нравится учить русский язык таким образом. Не скучно, а наоборот рабочие лиcmы, а также аудиозаписи заставляли меня слушать и заучивать словарный запас.

Результаты анкетирования показывают, что студентов устраивало содержание обучения и использованные методы обучения. 59,1\% студентов выразило готовность заниматься подготовкой рабочих материалов в домашних условиях и в случае очного обучения 
в будущем. Применяя метод перевернутого обучения, мы способствовали активному и самостоятельному обучению студентами иностранного языка. Кроме того, благодаря их усилиям, появилось более позитивное отношение к изучению профессионального русского языка. С другой стороны, мы должны упомянуть, что каждый метод имел некоторые недостатки. Основным недостатком было то, что студенты без присмотра и без личного присутствия однокурсников в аудитории не могли развивать коммуникативные навыки. Некоторым студентам было трудно заставить себя работать дольше без надзора преподавателя. Их самостоятельная работа дома, просмотр видео, а затем заполнение рабочих материалов требовали большой самодисциплины. Еще одним недостатком была трудоемкость заданий для студентов. Просмотр видео определенно занял больше времени, чем выполнение нескольких упражнений из учебника. Некоторые студенты могли чувствовать, что им не хватало личного объяснения содержания, словарного запаса со стороны преподавателя.

\section{6/ ЗАКЛЮЧЕНИЕ}

Мы пришли к выводу, что модель перевернутого обучения в условиях дистанционного обучения является эффективной, но имеет определенные ограничения в связи с потребностью значительного временного отрезка как при подготовке учебных материалов со стороны предодавателей, так и при выполнении учебных заданий студентами. Этот метод обучения ставит перед преподавателем сложную задачу подготовки подходящих материалов, но с другой стороны мотивирует студентов самостоятельно заниматься в домашней обстановке. Наше анкетирование показало, что студенты неравнодушны к изучению делового РКИ даже в условиях домашней подготовки под онлайн руководством преподавателя путем разработки рабочих листов. На наш взгляд, этот метод становится эффективнее, если занятия реализуются в классе и в домашней среде учащихся - не только дистанционно, с учетом перевернутой иерархии образовательных целей таксономии Блума.

\section{THE APPLICATION OF A FLIPPED CLASSROOM METHOD TO THE UNIVERSITY DISTANCE TEACHING OF BUSINESS RUSSIAN}

SUMMARY We came to the conclusion that our adapted flipped class model is effective but has certain limitations. In relation to distance teaching of Business Russian courses, the model is beneficial to both teachers and students. However, the method demands more personal involvement from both sides. Challenging aspects include time-consuming preparation of online materials in the form of worksheets from the side of the teacher and unguided, autonomous learning in the home environment from the side of the student. Our survey showed that students are willing to study and perform tasks not only in the classroom, but also outside the classroom in the conditions of home preparation. In our opinion, this method becomes more effective if classes are implemented in the classroom and in the home environment of students (not only in distance education) considering the inverted hierarchy of educational objectives of Bloom's taxonomy. 


\section{ЛИТЕРАТУРА}

I Атабекова А. А. - Белоусов А. А., 2013, В поиске ответов на вызовы образования XXI. века, Выстее образование сегодня, № 8, с. 19-24, https://docplayer.ru/59199781-Aunoaaiadaciaaiea-segodnya-nauki-yunoshey-pitayut-2-nichego-sebe-simvolicheskiy-kapitalvuza-64-kak-stat-liderom-3-24.html. [дата обращения: 22 января 2021 г.]

I Bergman J. - Sams A., 2012, Flip your classroom: Reach every student in every class every day, Eugene, ISTE, Alexandria, ASCD, 112 p., https://www.academia.edu/30809767/Jonathan_ Bergmann_Aaron_Sams_Flip_Your_Classroo_BookZZ_org_. [дата обращения: 22 января 2021 г.]

I Bergman J., 2013, Jon Bergmann Talks About Flipped Learning, video, https://www.youtube. com/watch?v=2ulyfwzvnDI. [дата обращения: 22 января 2021 г.]

I Bloom B., 1956, Taxonomy of educational objectives: The classification of educational goals. Handbook I: Cognitive domain, New York.

I Khan Academy, 2018, What is the history of Khan Academy, https://support.khanacademy.org/ hc/en-us/articles/202483180-What-is-the-history-of-Khan-Academy. [дата обращения: 22 января 2021 г.]

I Котане Л. В., 2014, Русский язык для делового общения А2. Учебное пособие: базовый курс изучения делового русского языка как иностранного, СПб.

I Lage M. J. - Platt G. J. - Treglia M., 2000, Inverting the classroom: A gateway to creating an inclusive learning environment, The Journal of Economic Education, 31(1), p. 30-43, https:// www.academia.edu/340051/Inverting_the_Classroom_A_Gateway_to_Creating_An_ Inclusive_Learning_Environment. [дата обращения: 22 января 2021 г.]

I Tsytovich M. V. - Boronenko G. F., 2018, Teaching Academic Writing in a Flipped Classroom, Вестник ЮУрГУ. Серия «Образование. Педагогические науки», Т. 10, № 2, c. 59-65, https://cyberleninka.ru/article/n/teaching-academic-writing-in-a-flippedclassroom/viewer. [дата обращения: 22 января 2021 г.] 